ECCOMAS

Proceedia
COMPDYN 2021

$8^{\text {th }}$ ECCOMAS Thematic Conference on Computational Methods in Structural Dynamics and Earthquake Engineering M. Papadrakakis, M. Fragiadakis (eds.) Streamed from Athens, Greece, 28 - 30 June 2021

\title{
THE EFFECT OF SOIL-STRUCTURE INTERACTION AND LIQUEFACTION ON THE SEISMIC VULNERABILITY OF TYPICAL PORT STEEL LIGHT-FRAME WAREHOUSES
}

\author{
Stella V. Karafagka ${ }^{1}$, Stavroula D. Fotopoulou ${ }^{1}$, Anna C. Karatzetzou ${ }^{1}$, Georgios E. \\ Malliotakis $^{2}$, and Dimitris Pitilakis ${ }^{1}$ \\ ${ }^{1}$ Aristotle University of Thessaloniki, Greece \\ e-mail: \{stellak,sfotopou,akaratze,dpitilakis\}@civil.auth.gr \\ ${ }^{2}$ University of Birmingham, UK \\ GXM054@student.bham.ac.uk
}

\begin{abstract}
Ports play a crucial role in the world economy, as they represent critical nodes in regional and national transportation networks. They are usually located in areas prone to geohazards, such as earthquakes and soil liquefaction. Although warehouses constitute a port system's key components, the published literature in the evaluation of their seismic vulnerability considering the effect of soil liquefaction and soil-structure interaction (SSI) is generally inadequate. To bridge this gap, this study's objective is to implement a numerical investigation of the influence of both liquefaction and SSI on the seismic vulnerability of typical port steel lightframe warehouses. The following numerical modelling approaches are applied: i) a $2 D$ fixedbase structure subjected to outcrop bedrock seismic motion neglecting SSI and liquefaction; ii) ) a 2D flexible-base model, considering both SSI and liquefaction; iii) a 3D fixed-base model which is subjected to outcrop bedrock seismic motion and thus neglecting both SSI and liquefaction; iv) a 3D fixed-base model subjected to a free-field motion that considers liquefaction. We conduct nonlinear incremental dynamic analysis for the above numerical approaches to derive seismic fragility and vulnerability curves considering (or not) SSI and/or liquefaction. The earthquake demand is determined based on the selection of actual earthquake records covering a wide range of seismic input motions in terms of amplitude, frequency content, and significant duration. The comparative results show the considerable role of liquefaction and SSI in altering the seismic fragility and port warehouses' vulnerability.
\end{abstract}

Keywords: Fragility, SSI, liquefaction, steel light-frame warehouse, numerical modelling. 


\section{INTRODUCTION}

Ports represent critical nodes in regional and national transportation networks, having an important impact on the world economy. Thus, resilience and continuous operation of port structures are interrelated with international, national, and regional growth and development. However, ports are usually located in areas prone to geohazards, such as earthquakes and soil liquefaction. Although warehouses, which are large space steel light-frame buildings (with or without masonry infills), constitute key components of a port system, the published literature in the evaluation of their induced physical damages due to the effect of ground shaking and soil liquefaction is generally inadequate. Also, soil-structure interaction (SSI) may play a significant role in the seismic performance of port structures, modifying their dynamic characteristics, as well as the seismic response at the foundation level. According to PIANC [1], most damage to coastal structures is the result of SSI; thus, design and analysis procedures should include both geotechnical conditions and structural conditions of coastal structures.

Usually, the seismic response of buildings is estimated assuming fixed-base conditions, which is reasonable solely for structures on stiff or rock-type soils. Nevertheless, the seismic response of a structure on soft soil may considerably differ compared to the fixed-base assumption [2]. In general, nonlinear soil behaviour and SSI effects on structures, either beneficial or detrimental, are well-studied [3-5]. Geometrical and material nonlinearities in the soilfoundation-structure system may detrimentally affect the dynamic behaviour of the structure, with respect to the soil characteristics and the intensity of the ground motion [6]. The problem is expected to be even more complicated when soil liquefaction phenomena are present.

Although some progress has already been made on the influence of ground shaking and soil liquefaction on the structural response and vulnerability of steel frame buildings [7-9], studies coupling both phenomena are limited. To estimate the seismic response of buildings, also considering liquefaction, more sophisticated methods can be used [10-11]. Within an effective stress site response concept, a "fully coupled approach" can be adopted that uses a plasticity-based constitutive model to predict both the pore pressure and the stress-strain response of the soil [12]. For estimating seismic performance and damages, the "coupled approach" has already been used for bridge systems [13-15], quay walls [16-17] and other simplified soil-structure systems [18-19]. However, its application to steel frame buildings on soils considering both liquefaction and SSI effects so as to estimate their physical seismic damages, needs further investigation.

To bridge this gap, we implement a numerical investigation of the influence of both SSI and liquefaction on the seismic vulnerability of typical port steel light-frame warehouses. The numerical modelling approaches used for the investigation are a 2D fixed-base structure neglecting SSI and liquefaction, a 2D flexible-base model considering both SSI and liquefaction, a 3D fixed-base model neglecting both SSI and liquefaction as well as a 3D fixed-base model subjected to a free-field motion that considers liquefaction. We conduct nonlinear incremental dynamic analysis for the above numerical approaches to derive seismic fragility and vulnerability curves considering (or not) SSI and/or liquefaction. Comparative results are presented showing the significant role of liquefaction and SSI in altering the seismic fragility and vulnerability of port warehouses.

\section{CONCEPTUAL MODELLING APPROACHES}

We developed four modelling approaches to produce fragility curves considering (or not) SSI and soil liquefaction:

i. a 2D fixed-base structure subjected to outcrop bedrock seismic motion neglecting SSI and soil liquefaction; 
ii. a 2D flexible-base model, considering both SSI and soil liquefaction. SSI is modelled by applying the direct approach. The soil and the structure are analysed as a single system, while liquefaction is considered by employing a fully coupled (u-P) formulation. Such a formulation is capable of simulating permanent shear-strain accumulation in clean medium-dense cohesionless soils during liquefaction and appropriate constitutive model for the examined soil profiles;

iii. a 3D fixed-base model which is subjected to outcrop bedrock seismic motion and thus neglecting both SSI and liquefaction and

iv. a 3D fixed-base model subjected to a free-field motion that considers liquefaction. This two-step uncoupled approach considers the liquefaction effects on the free-field response using the above described u-P formulation and appropriate constitutive model for the examined soil profiles. The free-field response is then applied to the fixedbase structure neglecting, thus, the SSI effects.

\section{NUMERICAL MODELLING}

\subsection{Selection of the structural building typology and soil profiles}

We study a typical steel light-frame warehouse, representative of Thessaloniki port critical buildings. Figure 1 and Figure 2 illustrate a representative cross-section and the floor plan respectively of the typical warehouse, as provided by Thessaloniki Port authorities and reproduced by the authors. The main characteristics of the building are set equal to total mass $\mathrm{m}=5.1 \mathrm{tn}$, fundamental period $\mathrm{T}_{\mathrm{o}}=0.30 \mathrm{~s}$, and yield strength $\mathrm{f}_{\mathrm{ym}}=235.0 \mathrm{MPa}$. Regarding the soil, we consider three representative soil profiles of the port area of Thessaloniki (Greece), simplified with respect to their total depth, denoted as SP1, SP2, and SP3 (Figure 3), based on the available geotechnical information of the port area and the available SPT and laboratory data [20-21]. The fundamental periods $T_{o}$ of the three soil profiles are equal to $0.88 \mathrm{~s}, 0.73 \mathrm{~s}$, and $0.64 \mathrm{~s}$, respectively. Figure 3 presents for all three soil profiles the variation of the shear wave velocities $V_{S}$ with depth together with a general geotechnical characterization according to the USCS soil classification scheme. The liquefaction potential of the subsoil layers of the selected soil profiles was quantitatively evaluated following the Eurocode 8 guidelines (EC8)- Part 5 (CEN 2004). For SP1, potentially liquefiable soil formations are found at depths $z=-9 \div-11 \mathrm{~m}$, $z=-14 \div-20 m$, and $z=-26.5 \div-36 m$, for SP 2 at depths $z=-3 \div-14 m$, while for SP 3 at depths $z=-$ $4 \div-20 \mathrm{~m}$, which are basically silty/clayey sands and non-plastic silts with low values of NSPT. Thus, knowing that the liquefaction susceptibility in the port area is rather high, these soil profiles refer to ground type S according to the EC8 soil classification scheme [22].

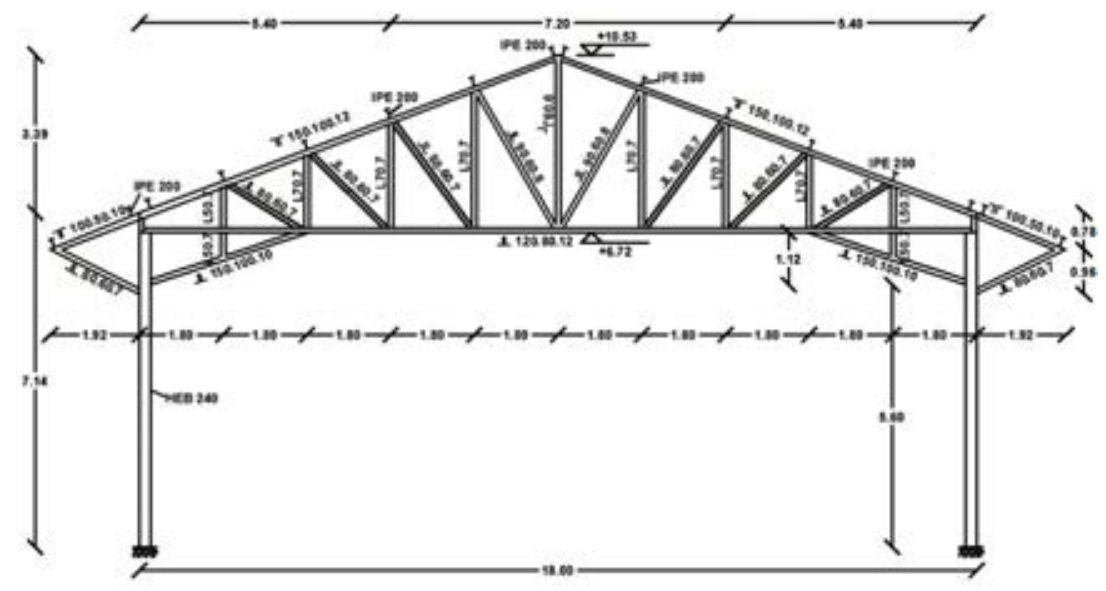

Figure 1: Cross-section of the typical warehouse. 


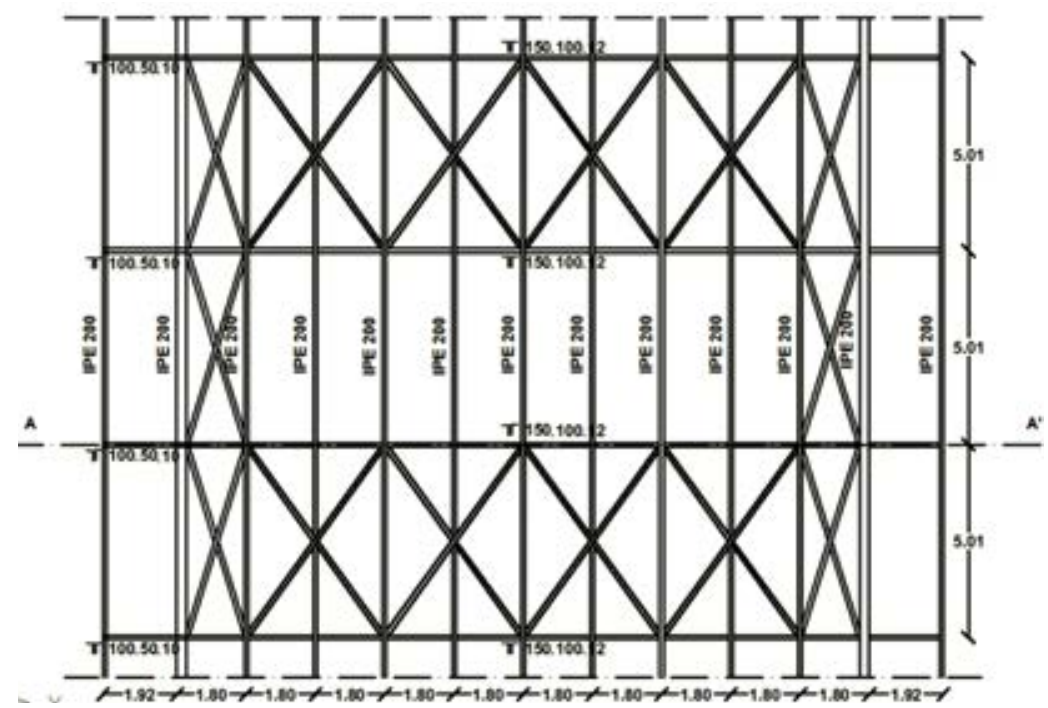

Figure 2: Plan view of the typical warehouse.
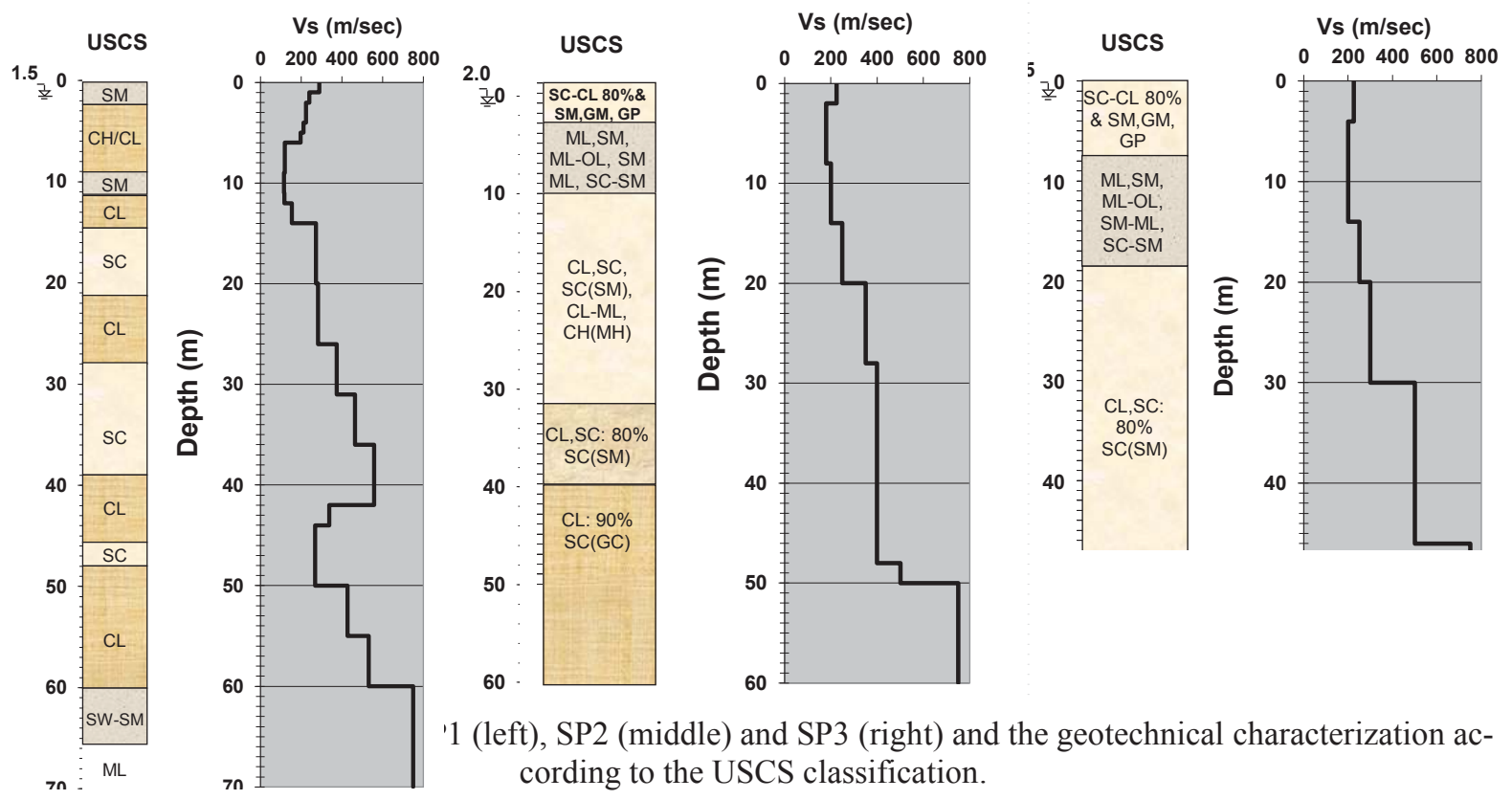

\subsection{Structural modelling}

In the former two conceptual modelling approaches (i.e., i. and ii.), two-dimensional (2D) numerical simulation of the reference building, as shown in Figure 4 left, is conducted using the open-source computational platform OpenSees [23]. Inelastic force-based formulations are implemented for the 2D, three- degree of freedom nonlinear beam-column frame elements modelling, while the roof (trusses) of the building is modelled using "truss" elements (with two degrees of freedom). The uniaxial "Steel01" material is used to construct a uniaxial bilinear steel material object with kinematic hardening. The main parameters required, i.e., the yield strength $\left(\mathrm{F}_{\mathrm{y}}\right)$, the initial elastic tangent $\left(\mathrm{E}_{0}\right)$, and the strain-hardening ratio (b), which is the ratio between post-yield tangent and initial elastic tangent, are taken equal to $\mathrm{F}_{\mathrm{y}}=235.0$ $\mathrm{MPa}, \mathrm{E}_{0}=2.1 \cdot 10^{5} \mathrm{MPa}$ and $\mathrm{b}=0.01$, respectively. The nonlinear beam-column frame elements are subjected to both axial compression and bending, considering five Gauss-Lobatto [24] integration points along each member's length. The applied formulations allow both geometric 
nonlinearities (P-delta and large displacements/rotation effects) and material inelasticity to be captured. Distributed material inelasticity along the element is applied based on the fibre approach to represent the cross-sectional behaviour [25]. Each fibre is associated with a uniaxial stress-strain relationship; the sectional stress-strain state of the beam-column elements is obtained through the integration of the nonlinear uniaxial stress-strain response of the individual fibres in which the section is subdivided. The truss elements are subjected only to axial compression. As they are constructed with a uniaxial material object, they consider strain-rate effects. The masses are applied as distributed along columns and beams (by assigning the specific weight of steel material) plus concentrated vertical loads on joints due to the existence of trusses in the normal direction.

In the latter two conceptual modelling approaches (i.e., iii. and iv.), three-dimensional (3D) numerical simulation of the reference building, as shown in Figure 4 right, is conducted using the SAP2000 finite element program [26]. For all sections, the S235 built-in steel material with isotropic symmetry type is used with the yield stress defined equal to $235 \mathrm{MPa}$ and the maximum tensile stress equal to $360 \mathrm{MPa}$. A parametric stress-strain curve is utilized to capture the nonlinear behaviour of the steel material comprising an initial linear region, a plastic plateau, a strain hardening region, and finally, a necking region leading to rupture. The main parameters required to construct the backbone stress-strain curve, i.e. the strain at yielding, the strain at the onset of strain hardening, the strain at maximum stress and the strain at rupture, are taken equal to 0.011 for yielding, 0.02 (end of the plateau), 0.14 and 0.20 , respectively. The kinematic hysteresis model is also considered, which is based upon kinematic hardening behaviour that is commonly observed in metals. This model dissipated a significant amount of energy and is appropriate for ductile materials. Under the rules of kinematic hardening, plastic deformation in one direction "pulls" the curve for the other direction along with it. Matching pairs of points are linked. Upon unloading and reverse loading, the curve follows a path made of segments parallel to and of the same length as the previously loaded segments and their opposite-direction counterparts until it re-joins the backbone curve when loading in the opposite direction. We use the fibre approach to represent the cross-sectional behaviour of the beams and columns, while the built-in steel frame sections are utilized to model trusses and braces sections. To consider nonlinear element behaviour, SAP2000 offers various hinges, such as uncoupled moment (M2 or M3), axial force (P), or hinges with axial force and moment interaction. Herein, we consider nonlinear behaviour for beams and columns elements using fibre hinges P-M2-M3, where the hinge force-deformation relationship is input manually, determined from the cross-section fibre model, while for trusses and braces elements, concentrated plastic hinges calculated according to FEMA are used. Once hinges are assigned, material nonlinearity may then characterize the inelastic response of frame elements. For columns and beams, in that way, each point represents a tributary area, having its unique stressstrain law. The axial stresses are integrated over the section to estimate the values of P, M2, M3. Fibre hinges are adapted more effectively to reality, even though they demand a lot of computational workloads. When it comes to strength loss, this is orientated by stress-strain law. In a cross-section, all fibres do not fail at the same time, and, thus, the overall hinges lose their capacity at a steady pace. For trusses and braces, axial hinge type is used. Generally, these sections are not stressed by bending or shear force but only from axial compression load. In addition, the plasticity is distributed at the edges of each element. The hinges behave according to elastoplastic perfectly plastic law, with maximum stress defined by yield point stress. Strength loss is considered to be extrapolated, since sudden loss is often unrealistic and may cause difficulties to analysis, leading to time consuming. 


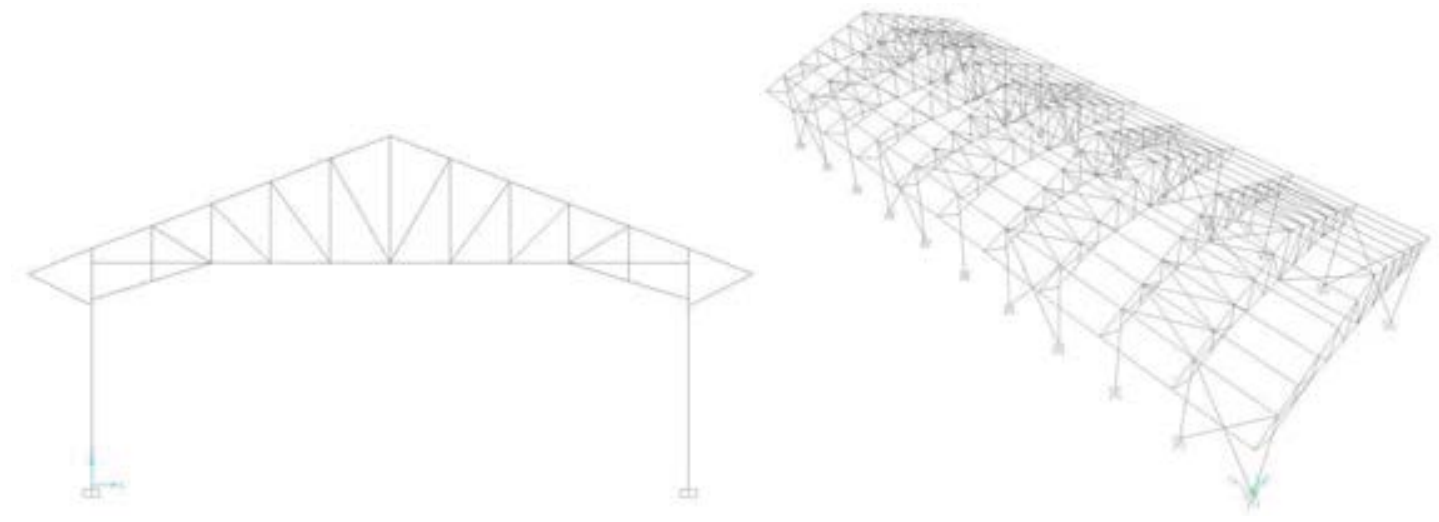

Figure 4: 2D (left) and 3D (right) numerical model of the warehouse.

\subsection{Soil modelling}

Each soil profile comprises several layers of cohesive and cohesionless soil material. The groundwater table is located at a depth of $1.5 \mathrm{~m}, 2.0 \mathrm{~m}$ and $1.5 \mathrm{~m}$ for the soil profiles SP1, SP2, and SP3, respectively (Figure 3). Saturated unit weights are used for the soil below this level and effective stress analysis is conducted using nine-node quadrilateral elements with both displacement and pore pressure degrees of freedom. Such elements are able to simulate fluidsolid coupling during the earthquake excitation, based on Biot's theory of porous medium [27]. To account for the finite rigidity of the underlying bedrock, a Lysmer-Kuhlemeyer [28] dashpot is incorporated at the base of the soil profile using a bedrock shear wave velocity of $627.0 \mathrm{~m} / \mathrm{s}, 750.0 \mathrm{~m} / \mathrm{s}$ and $750.0 \mathrm{~m} / \mathrm{s}$ for the soil profiles SP1, SP2 and SP3, respectively and a mass density of $2.2 \mathrm{Mg} / \mathrm{m}^{3}$. The Lysmer-Kuhlemeyer dashpot is assigned based on the viscous uniaxial material model and the 'zeroLength' element formulation at the same location, to connect the two previously defined dashpot nodes. This material model requires a dashpot coefficient that is defined according to Joyner and Chen [29] as the product of the mass density and the shear wave velocity of the underlying bedrock also including the base area of the soil profile. To model the underlying elastic half-space necessitates that the nodes at the base of the soil model are free to displace in the horizontal direction, are all given the same horizontal displacements and finally are fixed against vertical translation only. Mass and stiffness proportional Rayleigh damping is assigned to account for energy dissipation during seismic loading with a damping ratio equal to $2.0 \%$. Periodic boundary conditions are used to ensure that free-field conditions exist at the horizontal boundaries of the model. The displacement degrees of freedom for the nodes on either side of the soil model are tied together, imposing the same translational displacements in $\mathrm{x}$ and $\mathrm{z}$ directions, and rotation about the $\mathrm{y}$-axis. Each soil profile is excited at the base by a horizontal force time history proportional to the known velocity of the ground motion [29]. Due to the consideration of an elastic half-space it was possible to directly apply the outcropping rock motion at the base of the soil model [30].

We employ a fully coupled (u-P) formulation, capable of simulating permanent shearstrain accumulation in clean medium-dense cohesionless soils during liquefaction and dilation due to increased cyclic shear stiffness and strength. The soil constitutive behaviour is based on the framework of multi-surface plasticity [31], with modifications by Yang [32]. The hardening law, the yield surface and the flow rule constitute the major components of the plasticity model. During the application of the gravity load, at first the material behaviour is linear elastic, while in the second part of the gravity analysis the constitutive behaviour of the soil elements is changed to elastoplastic. In the subsequent dynamic loading phase, the stressstrain response is elastic-plastic. To generate soil hysteretic response under cyclic loading, we adopt a purely deviatoric kinematic hardening rule [31]. This kinematic rule dictates that all 
yield surfaces may translate in stress space within the failure envelope [32-33] and be consistent with the Masing unloading/reloading criteria [34]. For the cohesionless soil layers, an elastic-plastic material, namely "PressureDependMultiYield02", is used in Opensees, where the yield function is assumed to follow the Drucker-Prager shape and the yield surface is a function of friction angle and cohesion. Plasticity is formulated based on the multi-surface concept, with a non-associative flow rule [32] that handles the soil contractive/dilative behaviour during shear loading to achieve appropriate interaction between shear and volumetric responses. For the cohesive soil layers, an elastic-plastic material in which plasticity exhibits only in the deviatoric stress-strain response, namely "PressureIndependMultiYield", is used. The volumetric stress-strain response is linear-elastic and is independent of the deviatoric response. This material is implemented to simulate monotonic or cyclic response of materials whose shear behaviour is insensitive to the confinement change. The yield function is assumed to follow the Von Mises shape and the yield surface is a function solely of undrained shear strength. Plasticity is formulated based on the multi-surface concept, with an associative flow rule in which the incremental plastic strain vector is normal to the yield surface.

\subsection{Soil-structure interaction modelling}

For the 2D flexible-base model (modelling approach ii) the direct approach is applied, which accounts simultaneously inertial and kinematic interaction effects. Figure 5 represents the 2D coupled finite element (FE) soil-structure model for the warehouse resting on the liquefiable soil, which is subjected to combined ground shaking and liquefaction. The grids adapted for the different soils SP1, SP2, and SP3 have a total length three times their depth to avoid spurious wave reflections at the vertical boundaries. Their dimensions are defined equal to $60.0 \mathrm{~m} \times 180.0 \mathrm{~m}, 50.0 \mathrm{~m} \times 150.0 \mathrm{~m}$ and $46.0 \mathrm{~m} \times 138.0 \mathrm{~m}$, respectively. Dense discretization is achieved using quadrilateral elements of $0.5 \mathrm{~m} \times 2.0 \mathrm{~m}$, considering that the maximum frequency of interest is set to $10 \mathrm{~Hz}$. This mesh allows an adequate number of elements to fit within the shortest wavelength of the propagating shear wave.

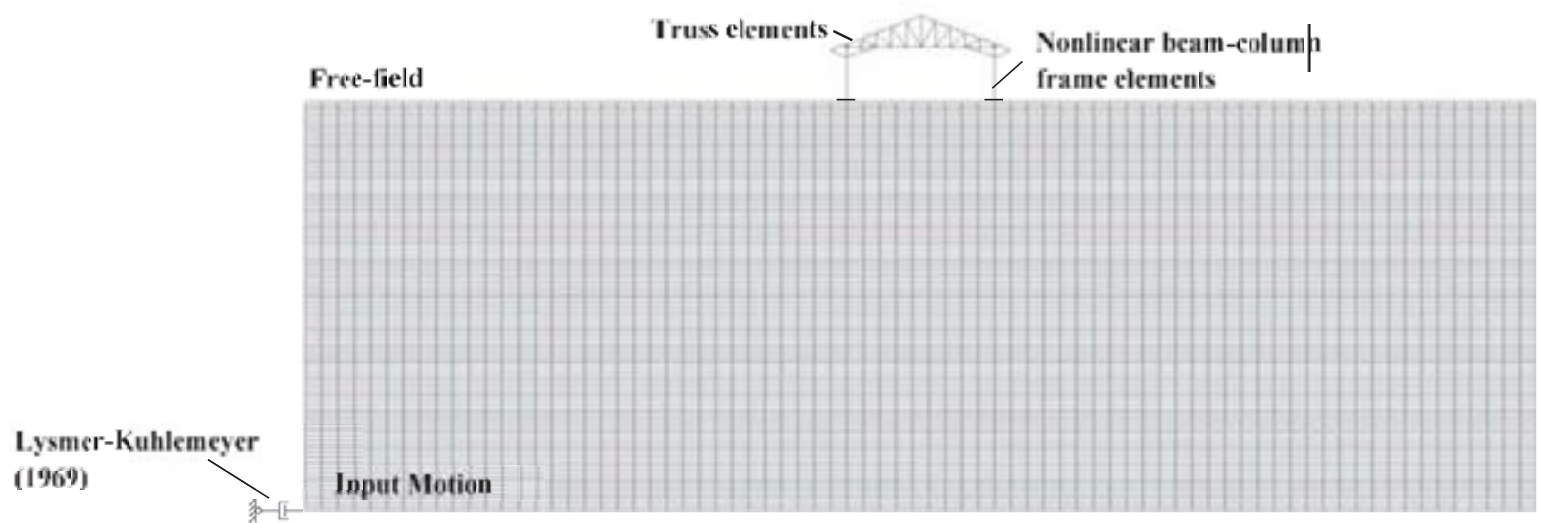

Figure 5: Finite element 2D model for the typical steel light-frame warehouse on liquefiable soil.

A full bond is assumed between the structure's foundation and the soil nodes. The soil and the structure nodes at the level of foundation have appropriate constraints in order to ensure equal displacements. Shallow, relatively flexible foundations are considered, modelled as elastic beam-column elements of infinite rigidity, which allow columns to move differentially. In this case, it is furthermore assumed that no interface has been considered between the structure and the foundation and that failure will take place on the structural elements of the building, while the structural integrity of the foundation itself will not be affected by the liquefaction induced deformation. 


\section{NUMERICAL ANALYSIS}

\subsection{Seismic input motion}

A representative set of fifteen real ground motion records (Table 1) is selected from the European Strong-Motion Database to perform nonlinear incremental dynamic analyses. They are all referring to rock type or stiff soils (ground types A and B according to EC8) with moment magnitude $\left(\mathrm{M}_{\mathrm{w}}\right)$ and epicentral distance $\mathrm{R}$ that range between $5.5<\mathrm{M}_{\mathrm{w}}<6.5$ and $0<\mathrm{R}<45 \mathrm{~km}$ respectively. The primary selection criterion is the average acceleration spectra of the set to match the corresponding 5\% damped median plus 0.5 standard deviations spectrum defined based on the ground motion prediction equation (GMPE) proposed by Akkar and Bommer [35]. The optimization procedure is performed using REXEL software [36] that allows obtaining combinations of accelerograms, which on average are compatible to the reference spectrum. Figure 6 shows the mean elastic response spectrum of the records in comparison with the corresponding median plus 0.5 standard deviations Akkar and Bommer [35] spectrum. As shown in the figure, a good match between the two spectra is achieved.

\begin{tabular}{|c|c|c|c|c|c|c|c|c|}
\hline $\begin{array}{l}\text { Earthquake } \\
\text { Name }\end{array}$ & Date & $\mathrm{M}_{\mathrm{w}}$ & $\begin{array}{l}\text { Fault } \\
\text { Mechanism }\end{array}$ & $\begin{array}{l}\text { Epicentral } \\
\text { Distance } \\
{[\mathrm{km}]}\end{array}$ & $\begin{array}{l}\mathrm{PGA}_{\text {initial }} \\
{\left[\mathrm{m} / \mathrm{s}^{2}\right]}\end{array}$ & $\begin{array}{l}\text { PGA corrected } \\
{\left[\mathrm{m} / \mathrm{s}^{2}\right]}\end{array}$ & $\begin{array}{l}\text { EC8 } \\
\text { Site } \\
\text { class } \\
\end{array}$ & $\begin{array}{l}\text { Waveform } \\
\text { ID }\end{array}$ \\
\hline Umbria & & & & & & & & \\
\hline $\begin{array}{l}\text { Marche } \\
\text { (aftershock) }\end{array}$ & 6/10/1997 & 5.5 & normal & 5 & 1.838 & 2.060 & $\mathrm{~A}$ & 651 \\
\hline Valnerina & 19/9/1979 & 5.8 & normal & 5 & 1.510 & 1.472 & $\mathrm{~A}$ & 242 \\
\hline $\begin{array}{l}\text { SE of Tira- } \\
\text { na } \\
\text { Lazio }\end{array}$ & 9/1/1988 & 5.9 & thrust & 7 & 4.037 & 3.826 & $\mathrm{~A}$ & 3802 \\
\hline $\begin{array}{l}\text { Abruzzo } \\
\text { (aftershock) }\end{array}$ & $11 / 5 / 1984$ & 5.5 & normal & 15 & 1.411 & 1.373 & A & 990 \\
\hline Valnerina & 19/9/1979 & 5.8 & normal & 5 & 2.012 & 2.060 & A & 242 \\
\hline Kozani & $13 / 5 / 1995$ & 6.5 & normal & 17 & 2.039 & 2.158 & $\mathrm{~A}$ & 6115 \\
\hline $\begin{array}{l}\text { Friuli } \\
\text { (aftershock) }\end{array}$ & 15/9/1976 & 6 & thrust & 12 & 1.339 & 1.373 & A & 149 \\
\hline $\begin{array}{l}\text { Umbria } \\
\text { Marche } 1\end{array}$ & 26/9/1997 & 5.7 & normal & 23 & 1.645 & 1.668 & A & 763 \\
\hline $\begin{array}{l}\text { Friuli } \\
\text { (aftershock) }\end{array}$ & $15 / 9 / 1976$ & 6 & thrust & 14 & 2.586 & 2.649 & B & 134 \\
\hline Patras & $14 / 7 / 1993$ & 5.6 & strike slip & 9 & 3.337 & 3.434 & B & 1932 \\
\hline Kalamata & $13 / 9 / 1986$ & 5.9 & normal & 11 & 2.670 & 2.747 & B & 414 \\
\hline $\begin{array}{l}\text { Umbria } \\
\text { Marche } 2\end{array}$ & 26/9/1997 & 6 & normal & 11 & 5.138 & 5.592 & B & 594 \\
\hline $\begin{array}{l}\text { Montenegro } \\
\text { (aftershock) }\end{array}$ & $24 / 5 / 1979$ & 6.2 & thrust & 17 & 1.708 & 1.766 & B & 229 \\
\hline $\begin{array}{l}\text { Kefallinia } \\
\text { island }\end{array}$ & 23/1/1992 & 5.6 & thrust & 14 & 2.223 & 2.060 & B & 6040 \\
\hline Ano Liosia & 7/9/1999 & 6 & normal & 14 & 2.159 & 2.256 & $\mathrm{~B}$ & 1714 \\
\hline
\end{tabular}

Table 1: List of records used for the dynamic analyses. 
These records are then filtered between 0.25 and $15.0 \mathrm{~Hz}$, using a fourth-order bandpass Butterworth type filter. Baseline correction linear type is also applied. Table 1 also presents the values of $\mathrm{PGA}_{\text {corrected }}$ obtained from the corrected accelerograms used for the analyses.

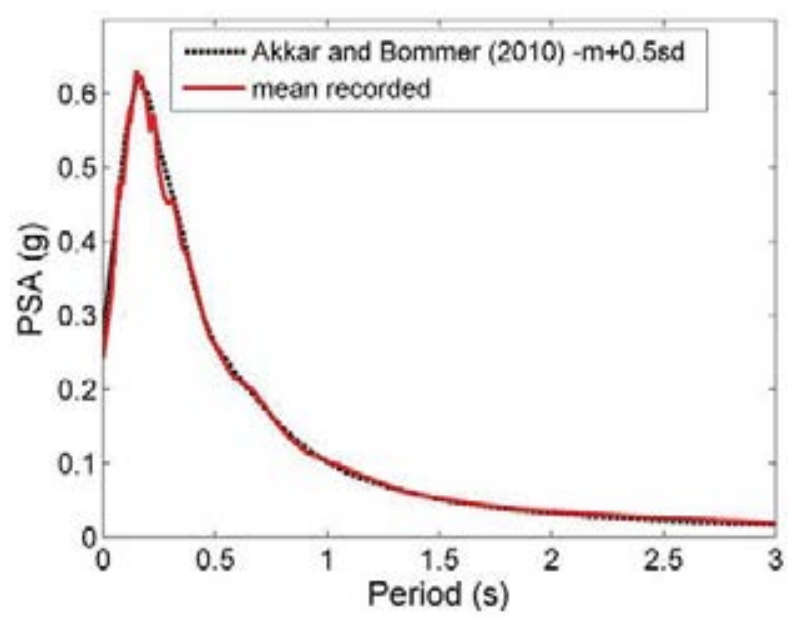

Figure 6: Average elastic response spectrum of the input motions in comparison with the corresponding median plus 0.5 standard deviations Akkar and Bommer [35] spectrum.

\subsection{Numerical analyses}

To examine the effect of liquefaction on the seismic ground response, we initially perform a comparative dynamic analysis of the considered nonlinear soil profiles. In this respect, the utilized earthquake records are scaled at PGA values equal to $0.05 \mathrm{~g}$ and $0.3 \mathrm{~g}$. For PGA equal to $0.05 \mathrm{~g}$, it seems that the soil responses are within the linear elastic range, since the effective confinement values with depth do not approach zero. On the contrary, for the dynamic analyses with input motions scaled at $0.30 \mathrm{~g}$, liquefaction is taking place. Layers of potential liquefaction may be identified by loss of effective confining stress at certain depths, which is verified by the relative stress-strain loops. Figure 7 shows representative results in terms of effective confinement with depth and stress-strain hysteretic loops at specific depth (i.e., $7 \mathrm{~m}$ below surface) indicatively for Soil profile SP2 and Montenegro (aftershock) input motion scaled at $0.05 \mathrm{~g}$ and $0.3 \mathrm{~g}$.

Moreover, an initial elastic modal analysis of both the 2D and 3D fixed-base models is conducted to define the dynamic characteristics of the structure and increase the reliability of the proposed modelling approaches. The fundamental period of the studied structure is computed equal to $0.298 \mathrm{~s}$ for the 2D fixed-base model and $0.293 \mathrm{~s}$ for the corresponding 3D fixed-base model providing a first verification of their validity.

\subsection{Incremental dynamic analysis}

2D and 3D incremental dynamic analysis (IDA) is then conducted to estimate more thoroughly the seismic performance of the typical steel light-frame warehouse due to ground shaking and liquefaction. To express the scaling level an initial, temporary choice of an intensity measure (IM) is needed. Scaling can be re-expressed in any other scalable IM [37] after the runs are performed. In this study, the IM is initially described by the peak ground acceleration on rock outcropping conditions $\left(\mathrm{PGA}_{\text {rock }}\right)$. This IM is considered more appropriate due to its simplicity. Hence, IDA for the fixed-base and the three SSI models is conducted by applying the 15 progressively scaled records, considering a first elastic run at $0.05 \mathrm{~g}$, an initial step of $0.1 \mathrm{~g}$ and a step increment of $0.1 \mathrm{~g}$. A sequence of at least ten runs is performed on 
each record. The damage measure (DM) is expressed in terms of maximum inter-story drift (maxISD), which is known to relate well to dynamic instability and structural damage of frame buildings.
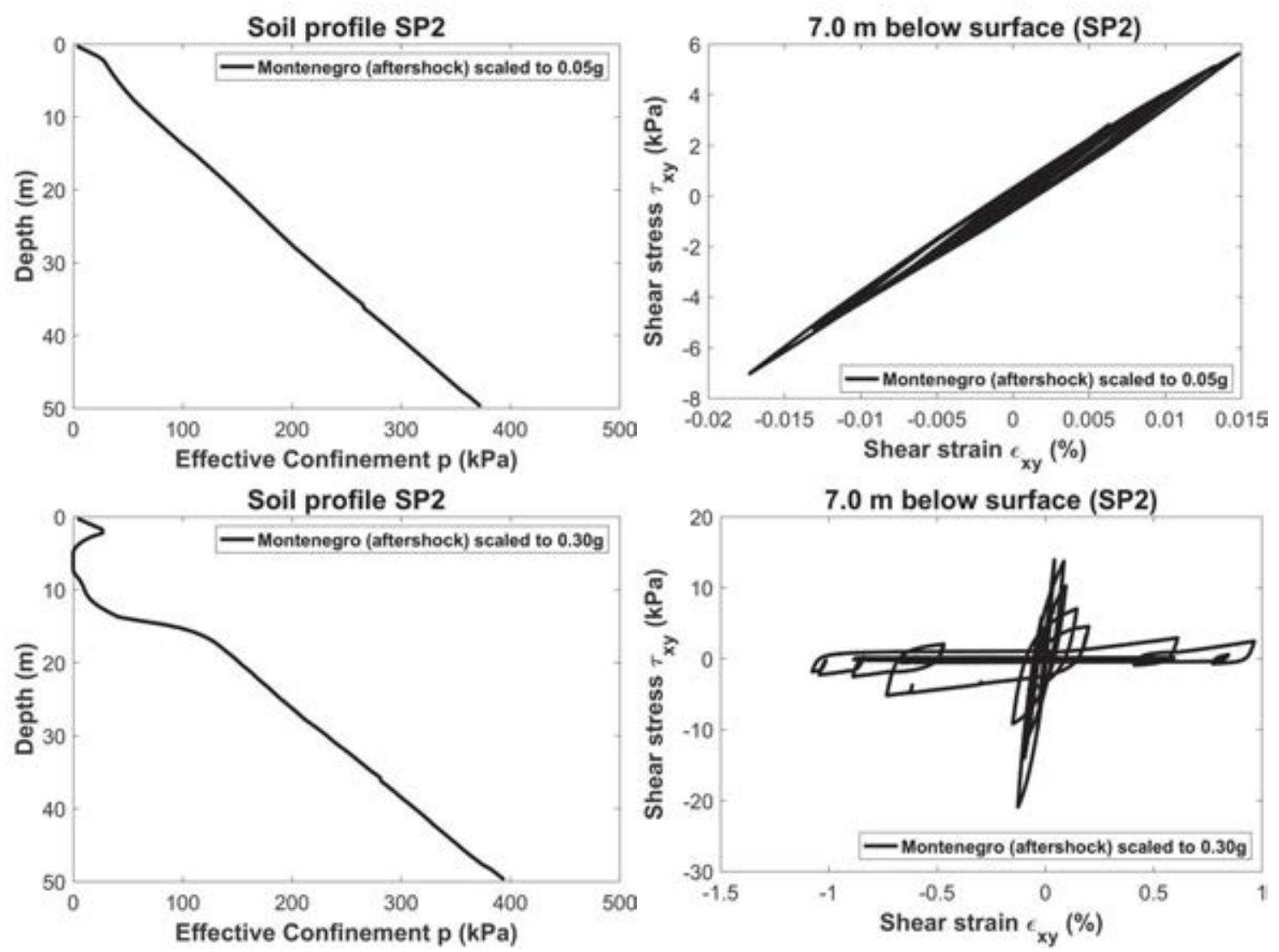

Figure 7: Variation of the effective confinement with depth and stress strain hysteretic loops at specific depth for SP2 and Montenegro (aftershock) input motion scaled at $0.05 \mathrm{~g}$ (top) and $0.3 \mathrm{~g}$ (bottom)

\section{FRAGILITY AND VULNERABILITY CURVES}

\subsection{Definition of limit states}

A key factor for the vulnerability assessment is the accurate definition of damage limit states as they directly influence the evaluation of the fragility function parameters. Four damage states are defined in terms of maxISD ratio, describing the exceedance of slight, moderate, extensive, and complete damage of light-weight steel warehouses. According to NIBS [38], "Steel Light Frames" structures are mostly single storey structures combining rod-braced frames in one direction and moment frames in the other. Due to the repetitive nature of the structural systems, the type of damage to structural members is expected to be rather uniform throughout the structure. Consequently, warehouses are considered as "Steel Light Frames" structures. The qualitative description of each damage state for steel light-frame structures adopted in this research work can be found in NIBS [38]. Usually, the damage limit states are defined on the IDA curves derived for the fixed-base building subjected to ground shaking, with the complete/collapse damage limit state placed at a point where the IDA curve is leaning towards the flatline. The damage limit states are selected based on the existing literature $[7,38]$ combined with the IDA analysis results and objective engineering criteria. The adopted damage limit state values are shown in Table 2. 


\begin{tabular}{cc}
\hline Limit states & Steel light-frame warehouse \\
\hline LS 1 & $0.50 \%$ \\
LS 2 & $1.00 \%$ \\
LS 3 & $2.00 \%$ \\
LS 4 & $3.30 \%$ \\
\hline
\end{tabular}

Table 2: Limit state values in terms of maxISD adopted for steel warehouse.

\subsection{Development of fragility and vulnerability curves}

A fragility curve describes the probability of exceeding a specific damage state under a seismic excitation of a given intensity. They can be produced taking advantage of the results of the nonlinear IDA in terms of PGA and maxISD ratio, as two parameters are required for the lognormal distribution functions given from the following equation:

$$
P\left[L S_{i} / I M\right]=\Phi\left(\frac{\ln (I M)-\ln \left(\overline{I M}_{i}\right)}{\beta}\right)
$$

where $\Phi$ is the standard normal cumulative distribution function, $\mathrm{LS}_{\mathrm{i}}$ is the damage limit state, $\mathrm{IM}$ is the intensity measure of the earthquake expressed both in terms of rock outcropping PGA rock measure in $\mathrm{g}, \overline{I M}$ and $\beta$ are the corresponding median values at which the building reaches each damage limit state, $\mathrm{i}$, and log-standard deviations respectively. A linear regres-

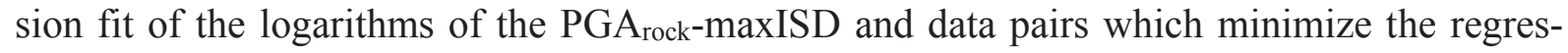
sion residuals is adopted. Three components of uncertainty are accounted for related to the definition of the limit state value $\beta_{L S}$ (defined empirically as $\beta_{L S}=0.4$ ), the capacity of each structural type $\beta \mathrm{c}$ (defined empirically as $\beta_{\mathrm{c}}=0.30$ ), and the demand $\beta_{\mathrm{D}}$ [38]. The demand $\beta_{\mathrm{D}}$ is calculated conducting statistical processing of the numerical results (IM-DM data pairs). In

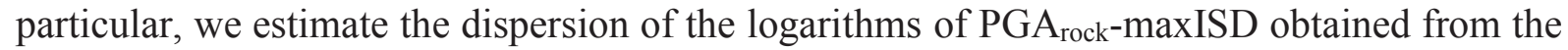
numerical analysis using the regression fit. The total parameter $\beta$, which represents the total dispersion related to each fragility curve, is finally evaluated as the root of the sum of the squares of the three variability dispersions assuming that they are statistically independent [38]. Figure 8 shows the derived fragility curves along with their fragility parameters (median $\overline{I M}$ and $\log$-standard deviation $\beta$ ) in terms of $\mathrm{PGA}_{\text {rock }}$ for the steel light-frame warehouse subjected to ground shaking considering the different approaches.

From Figure 8 some interesting conclusions could be derived. First of all, it is noticed, that $2 \mathrm{D}$ and 3D configurations for the fixed-base structure, ignoring liquefaction and SSI effects, are generally correlated quite well with the 3D fixed-base model showing lower vulnerability values for all damage states. Secondly, it seems that the vulnerability of a steel light-frame warehouse, when considering liquefaction effects, is very low. More specifically, for PGA rock values up to $2.0 \mathrm{~g}$, the $2 \mathrm{D}$ flexible-base and the $3 \mathrm{D}$ fixed-base models that consider liquefaction are almost no damaged. For PGA rock higher than $2.0 \mathrm{~g}$, only the "Slight" damage state exists while fragility curves for the other damages are not proposed. A third important conclusion is that the effect of SSI is not significant for the 2D and 3D models which consider liquefaction. Thus, the proposed fragility curve for slight damage state is almost identical for the 2D flexible-base and the 3D fixed-base models implying that the influence of SSI is not of paramount importance for this specific structure. 

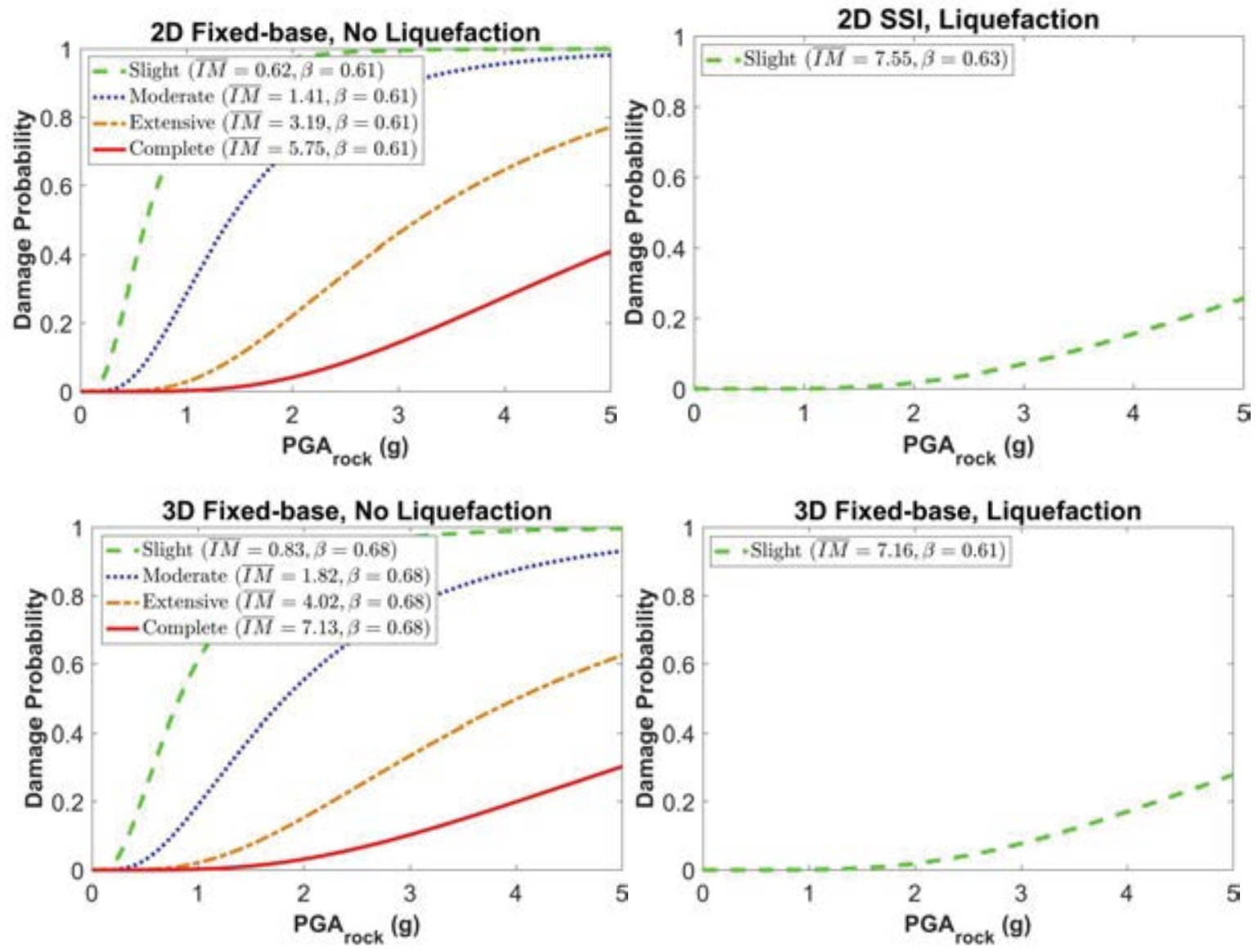

Figure 8: Fragility curves in terms of $\mathrm{PGA}_{\text {rock }}$ for the steel light-frame warehouse subjected to ground shaking considering the different approaches.

Next, for the 3D fixed-base approach neglecting liquefaction, we perform a comparison between the herein resulted fragility curves with the ones proposed by Nazri et al. [7] for similar structures (Figure 9). For the "slight" and "moderate" damage states fragility curves are in quite good agreement. For the rest two damage states the correlation between the two approaches is not that good. This is due among other factors to the differences on the structural characteristics and the definition of the complete damage limit state.

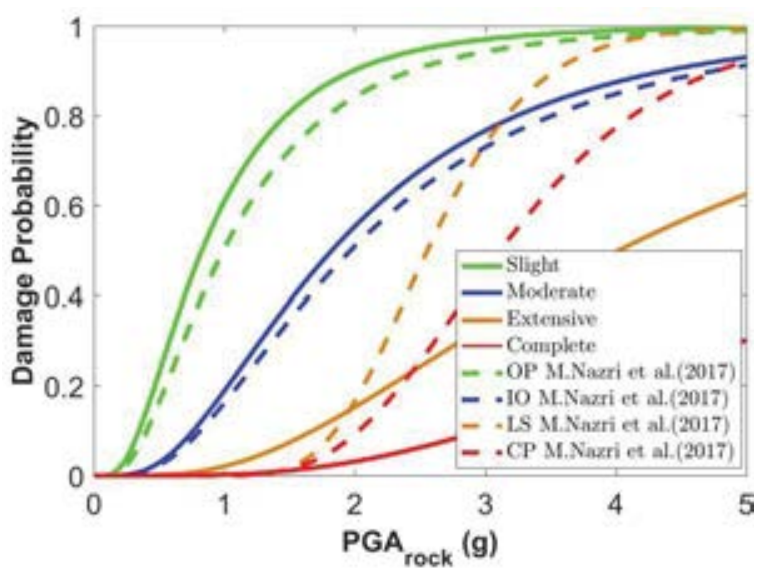

Figure 9: Comparison of the proposed fragility curves for the warehouse using the 3D fixed-base approach neglecting liquefaction with the corresponding analytical ones of Mohamed Nazri et al. [7]. 
Once the probabilities of exceeding the predefined damage limit states are calculated, the vulnerability (or damage) index $\mathrm{d}_{\mathrm{m}}$ for each level of seismic intensity can be estimated according to the following expression:

$$
d_{m j}=\sum_{i=1}^{4} P_{i j} \cdot d_{i}
$$

where $\mathrm{d}_{\mathrm{mj}}$ is the damage index (taking values from 0 : no damage to 1 : complete damage) corresponding to each seismic intensity level $\mathrm{j}, \mathrm{P}_{\mathrm{ij}}$ is the discrete damage probability for each damage limit state and di is the damage index at each damage limit state.

Following NIBS [38], we set the central value of the damage index at each damage limit state for the RC buildings equal to $0.10,0.15,0.40$ and 0.80 for the LS1 (minor), LS2 (moderate), LS3 (extensive) and LS4 (complete), respectively. A vulnerability curve is then generated which provides a unique damage index for each level of seismic intensity.

Figure 10 shows the derived vulnerability curves in terms of $\mathrm{PGA}_{\text {rock }}$ for the warehouse subjected to ground shaking considering the different approaches. We observe that the vulnerability of the 2D and 3D fixed-base configurations is in good agreement. When liquefaction is considered, the vulnerability decreases. This is due to the increased nonlinear behaviour of the soil profile introduced by the liquefaction. The 3D fixed-base, and the $2 \mathrm{D}$ flexible models that consider soil liquefaction, give almost the same vulnerability curve, which shows that the consideration of SSI has no considerable effect on the vulnerability of the structure.

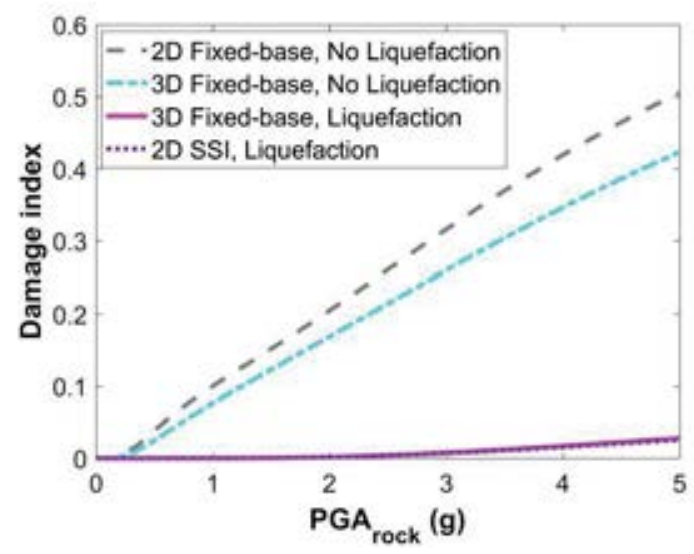

Figure 10: Vulnerability curves in terms of $\mathrm{PGA}_{\text {rock }}$ for the steel light-frame warehouse subjected to ground shaking considering the different approaches.

\section{CONCLUSIONS}

Within this study's framework, incremental dynamic analysis was performed for a typical port steel light-frame warehouse using a selected set of earthquake records considering four different modelling approaches. This study aimed to identify soil liquefaction and SSI's role in altering the seismic fragility and vulnerability of port warehouses.

1. We concluded that $2 \mathrm{D}$ and $3 \mathrm{D}$ configurations for the fixed-base structure, ignoring liquefaction and SSI effects, are generally correlated reasonably well with the 3D fixed-base model showing lower vulnerability values for all damage states.

2. Secondly, it seems that the vulnerability of a steel light-frame warehouse, when considering soil liquefaction effects, is very low, possibly due to the increased nonlinear behaviour of the soil profile introduced by the liquefaction.

3. A third important conclusion is that the impact of SSI is not significant for the $2 \mathrm{D}$ and 3D models which consider soil liquefaction. Thus, the proposed fragility curve 
for slight damage state is almost identical for the 2D flexible-base and the 3D fixed-base models implying that the influence of SSI is not of paramount importance for this specific structure.

\section{ACKNOWLEDGMENTS}

The research reported in this paper was carried out in the framework of the "Resilient, system-wide seismic risk assessment of port facilities. Application to Thessaloniki Port system", RESPORTS project (http://resports.gr/), funded by the Hellenic Foundation for Research and Innovation (HFRI) and General Secretariat for Research and Technology (GSRT) under Grant Agreement Number 754.

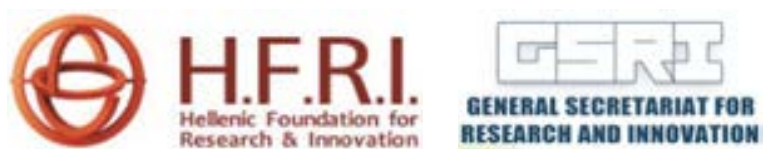

\section{REFERENCES}

[1] PIANC - International Navigation Association, Seismic design guidelines for port structures, Chairman: Iai S, Bakelma Publishers, Tokyo, 2001.

[2] G. Mylonakis, G. Gazetas, Seismic soil-structure interaction: beneficial or detrimental. $J$ Earthq Eng, 4(3), 277-301, 2000.

[3] M. Ciampoli, P Pinto. Effects of soil-structure interaction on inelastic seismic response of bridge piers. J Struct Eng ASCE, 121(5), 806-814, 1995.

[4] S. Karapetrou, S. Fotopoulou, K. Pitilakis, Seismic vulnerability assessment of high-rise non-ductile RC buildings considering soil-structure interaction effects. Soil Dyn Earthq Eng, 73, 42-57, 2015.

[5] C. Petridis, D. Pitilakis, Fragility curve modifiers for RC dual buildings to include nonlinear site effects and SSI. Earthq Spectra, 36(4), 1930-1951, 2020.

[6] D. Pitilakis, A. Modaressi-Farahmand-Razavi, D. Clouteau, Equivalent-Linear Dynamic Impedance Functions of Surface Foundations. J Geotech Geoenviron Eng, 139(7), 1130-1139, 2013.

[7] F. Mohamed Nazri, S. Tahar, S.N.A. Saruddin, S. Shahidan, Seismic Fragility Curves of Industrial Buildings by Using Nonlinear Analysis. MATEC Web of Conferences, 103, 02017, 2017.

[8] I. Ntaliakouras, N. Pnevmatikos, Seismic vulnerability curves for industrial steel structures. Proceedings of the $16^{\text {th }}$ European Conference on Earthquake Engineering, 18-21 June, Thessaloniki, Greece, 2017.

[9] S. Karafagka, S. Fotopoulou, K. Pitilakis, Vulnerability assessment of RC buildings and warehouses due to liquefaction displacements. Proceedings of the $16^{\text {th }}$ European Conference on Earthquake Engineering, 18-21 June, Thessaloniki, Greece, 2018.

[10] S. Karafagka, S. Fotopoulou, D. Pitilakis, Fragility curves of non-ductile RC frame buildings on saturated soils including liquefaction effects and soil-structure interaction. Bull Earthq Eng, https://doi.org/10.1007/s10518-021-01081-5, 2021. 
[11] S. Karafagka, S. Fotopoulou, D. Pitilakis, Fragility assessment of non-ductile RC frame buildings exposed to combined ground shaking and soil liquefaction considering SSI. Eng Struct 229, 111629, https://doi.org/10.1016/j.engstruct.2020.111629, 2021.

[12] G. Tropeano, A. Chiaradonna, A. D'Onofrio, F. Silvestri, A numerical model for nonlinear coupled analysis of the seismic response of liquefiable soils. Comput Geotech, 105, 211-227, 2019.

[13] M. Bowers, Seismic fragility curves for a typical highway bridge in Charleston, SC considering soil-structure interaction and liquefaction effects. MSc Thesis, No 285, Clemson University, 2007.

[14] B. Aygün, L. Dueñas-Osorio, J.E. Padgett, R. DesRoches, Efficient longitudinal seismic fragility assessment of a multispan continuous steel bridge on liquefiable soils. $J$ Bridge Eng ASCE, 16(1), 93-107, 2011.

[15] Z. Wang, L. Dueñas-Osorio, J.E. Padgett, Influence of Soil-Structure Interaction and Liquefaction on the Isolation Efficiency of a Typical Multispan Continuous Steel Girder Bridge. J Bridge Eng ASCE, 19(8), 2014.

[16] K. Ichii, Application of Performance-Based Seismic Design Concept for Caisson-Type Quay Walls. PhD Dissertation, Kyoto University, 2003.

[17] K. Ichii, Fragility Curves for Gravity-Type Quay Walls Based on Effective Stress Analyses. Proceedings of the 13 ${ }^{\text {th }}$ World Conference on Earthquake Engineering, 2004.

[18] S. Koutsourelakis, J.H. Prevost, G. Deodatis, Risk assessment of an interacting structure-soil system due to liquefaction. Earthq Eng Struct Dyn, 31(4), 851-879, 2002.

[19] F. Lopez-Caballero, A. Modaressi Farahmand-Razavi, Numerical simulation of liquefaction effects on seismic SSI. Soil Dyn Earthq Eng, 28(2), 85-98, 2008.

[20] A. Anastasiadis, D. Raptakis, K. Pitilakis, Thessaloniki's detailed microzoning: subsurface structure as basis for site response analysis. Pure Appl Geophys, 158(12), 25972633, 2001.

[21] K. Pitilakis, S. Argyroudis, S. Fotopoulou, S. Karafagka, K. Kakderi, J. Selva, Application of stress test concepts for port infrastructures against natural hazards. The case of Thessaloniki port in Greece. Reliab Eng Syst Saf, 184, 240-257, 2019.

[22] CEN, EN 1998-5. Eurocode 8: Design of structures for earthquake resistance - Part 5: Foundations, retaining structures and geotechnical aspects. European Committee for Standardization, Brussels, 2004.

[23] S. Mazzoni, F. McKenna, M.H. Scott, G.L. Fenves, Open system for earthquake engineering simulation user command-language manual. Berkeley, California: Pacific Earthquake Engineering Research Centre, 2009.

[24] A. Neuenhofer, F.C. Filippou, Evaluation of nonlinear frame finite-element models. $J$ Struct Eng ASCE, 123(7), 958-966, 1997.

[25] E. Spacone, V. Ciampi, F.C. Filippou, Mixed formulation of nonlinear beam finite element. Comput Struct, 58(1), 71-83, 1996.

[26] Computers and Structures Inc., SAP 2000-Structural Analysis Program: Linear and Nonlinear Static and Design of Three-dimensional structures. Berkeley, California, USA, 2004. 
[27] M.A. Biot, Mechanics of deformation and acoustic propagation in porous media. $J$ Appl Phys, 33(4), 1482-1498, 1962.

[28] J. Lysmer, A.M. Kuhlemeyer, Finite dynamic model for infinite media. J Eng Mech Div ASCE, 95, 859-877, 1969.

[29] W.B. Joyner, A.T.F. Chen, Calculation of nonlinear ground response in earthquakes. Bull Seismol Soc of Am, 65(5), 1315-1336, 1975.

[30] A.O.L. Kwok, J.P. Stewart, Y.M. Hashash, N. Matasovic, R. Pyke, Z. Wang, Z. Yang, Use of exact solutions of wave propagation problems to guide implementation of nonlinear seismic ground response analysis procedures. J Geotech Geoenviron Eng ASCE, 133(11), 1385-1398, 2007.

[31] J.H. Prevost, A simple plasticity theory for frictional cohesionless soils. Soil Dyn Earthq Eng, 4(1), 9-17, 1985.

[32] Z. Yang Z, Numerical Modeling of Earthquake Site Response Including Dilation and Liquefaction. PhD Thesis, Department of Civil Engineering and Engineering Mechanics, Columbia University, New York, 2000.

[33] E. Parra, Numerical modelling of liquefaction and lateral ground deformation including cyclic mobility and dilation response in soil systems. $\mathrm{PhD}$ thesis, Department of Civil Engineering, Rensselaer Polytechnic Institute, Troy, New York, 1996.

[34] G. Masing, Eigenspannungen and verfertigung beim messing. Proceedings of the $2^{\text {nd }}$ International Congress for Applied Mechanics, Zurich, Switzerland, 1926.

[35] S. Akkar, J.J. Bommer, Empirical equations for the prediction of PGA, PGV and spectral accelerations in Europe, the Mediterranean and the Middle East. Seismol Res Lett, 81, 195-206, 2010.

[36] I. Iervolino, C. Galasso, E. Cosenza, REXEL: computer aided record selection for codebased seismic structural analysis. Bull Earthq Eng, 8(2), 339-362, 2010.

[37] D. Vamvatsikos, C.A. Cornell, Incremental dynamic analysis. Earthq Eng Struct Dyn, 31(3), 491-514, 2002.

[38] National Institute of Building Sciences -NIBS, Direct physical damage-general building stock. HAZUS-MH Technical manual, Chapter 5. Washington, D.C.: Federal Emergency Management Agency, 2004. 